\title{
Aspects relating to the reliability calculation of the cutting-teeth mounted on the bucket wheel excavators used in lignite mining
}

\author{
Ovidiu-Bogdan Tomuș ${ }^{1, *}$, Andrei Andraș ${ }^{1}$, Dumitru Jula ${ }^{1}$ and Stela Dinescu ${ }^{1}$ \\ ${ }^{1}$ University of Petroşani. Dept. of Mechanical, Industrial and Transports Engineering, Romania
}

\begin{abstract}
The paper deals with the calculation of the operational reliability for the cutting-teeth mounted on bucket wheel excavators used in lignite extraction in the Oltenia Basin. Based on the data recorded for three types of cutting-teeth used in production, a reliability study has been carried out which determines the main reliability indicators of the quality level of these cutting-teeth. The study compares the constructive and functional characteristics of the three types of cutting-teeth, which is the basic criterion for purchasing a certain type of cutting-tooth, as well as for the supply of spare parts.
\end{abstract}

Keywords: Reliability, Cutting-teeth, BWE, Lignite, Open pit mining

\section{Introduction}

Four types of bucket wheel excavators (BWE), EsRc-470-15 / 3,5-400, SRS-1300-26 / 3,5500, SRS-2000-30 / 7-2 × 500, and EsRc-1400-30 / 7-630, are used in lignite open pit mines in the Oltenia Coal Basin [1].

In figure 1 a chisel type tooth is presented, and the representative geometric parameters defining the shape of the tooth are specified. The teeth that equip the BWE bucket are designed to displace the material from the face and guide it towards the inside of the bucket. The teeth are mounted on the buckets with bolts or by wedging in cassettes [2].

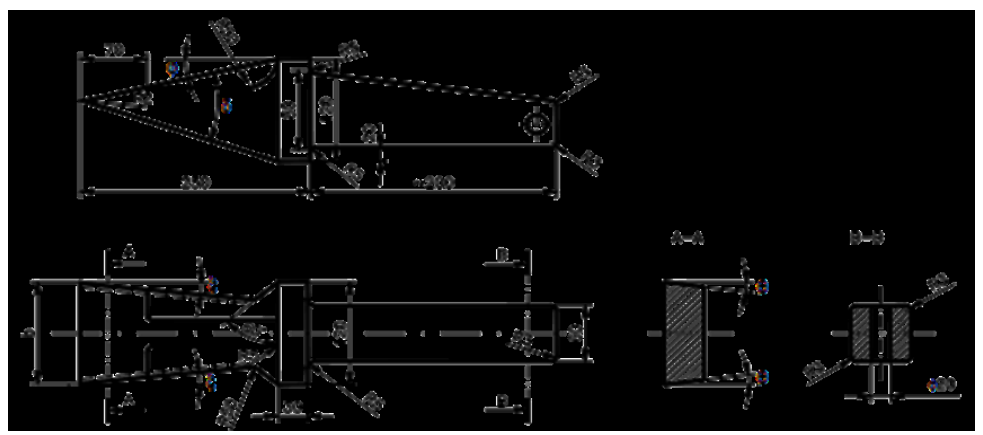

Fig. 1. Dimensions and parameters of a chisel type BWE cutting teeth.

\footnotetext{
${ }^{*}$ Corresponding author: tobogdan2002@yahoo.com
} 
There are three types of cutting teeth on the market that can fit the buckets of these BWEs. For the study, the supply company A, supplies cutting teeth of types 1400-MII and 1400-3GX, and another company, called B, delivers tooth type 1300-A0M.

Since the working conditions of the teeth are very different, it is necessary to use statistical calculations of their actual operating time. This is done by performing a reliability study that best shows the behavior of the teeth. The study is conducted by reallife testing of three representative samples of each of the three types of teeth.

When testing under the actual operating conditions of the three types of teeth, the admissible wear limits must be considered. The maximum permissible wear limits (maximum wear of tooth), depending on the construction variant, are:

Type $1300-\mathrm{A} 0 \mathrm{M}=50 \mathrm{~mm}$;

Type $1400-\mathrm{MII}=115 \mathrm{~mm}$;

Type $1400-3 \mathrm{GX},=125 \mathrm{~mm}$.

Replacing of the teeth when they reach this level of wear is strictly necessary for at least three reasons. The first is to avoid increasing the energy consumption for the bucket-wheel drive. The second is to avoid damaging the buckets and the bucket-wheel. An finally, the maintenance of the used tooth in the allowances for reconstruction and hardening [3].

\section{Estimation of the average usage time of 1400-MII type cutting tooth}

During excavation, the cutting teeth are subjected to composed bending stresses in two perpendicular directions and to compression along the longitudinal axis direction. There are also crushing stresses in the area where they are attached to the bucket and shocks due to the unevenness of excavated rocks. Very important is the high and aggressive mechanical abrasion that occurs in the area of the active part (the tip of the teeth), which is decisive in determining the level of tooth reliability [4].

The field studies for the 1400-MII type cutting teeth were performed on EsRc-1400 excavators in the Berbești and Roşia open pit mines on a sample of 70 teeth.

Effective operating times to failure (change due to wear above the permissible limit), in hours, form the statistical series of type (S1) shown in table 1.

Table 1. Values of the operating time until failure for the cutting teeth type 1400-MII

\begin{tabular}{|c|c|c|c|c|c|c|c|c|c|c|c|c|c|c|c|c|c|}
\hline No. & $\begin{array}{c}T_{i}, \\
h r s\end{array}$ & No. & $\begin{array}{c}T_{i}, \\
h r s\end{array}$ & No. & $\begin{array}{c}T_{i}, \\
h r s\end{array}$ & No. & $\begin{array}{c}T_{i}, \\
h r s\end{array}$ & No. & $\begin{array}{c}T_{i}, \\
h r s\end{array}$ & No. & $\begin{array}{c}T_{i}, \\
h r s\end{array}$ & No. & $\begin{array}{c}T_{i}, \\
h r s\end{array}$ & No. & $\begin{array}{c}T_{i}, \\
h r s\end{array}$ & No. & $\begin{array}{c}T_{i}, \\
h r s\end{array}$ \\
\hline 1 & 95 & 9 & 165 & 17 & 198 & 25 & 261 & 33 & 300 & 41 & 382 & 49 & 463 & 57 & 552 & 65 & 597 \\
\hline 2 & 97 & 10 & 170 & 18 & 200 & 26 & 265 & 34 & 300 & 42 & 387 & 50 & 465 & 58 & 580 & 66 & 600 \\
\hline 3 & 97 & 11 & 172 & 19 & 200 & 27 & 273 & 35 & 300 & 43 & 392 & 51 & 489 & 59 & 580 & 67 & 600 \\
\hline 4 & 98 & 12 & 180 & 20 & 200 & 28 & 279 & 36 & 300 & 44 & 395 & 52 & 493 & 60 & 590 & 68 & 600 \\
\hline 5 & 99 & 13 & 180 & 21 & 200 & 29 & 283 & 37 & 352 & 45 & 398 & 53 & 495 & 61 & 591 & 69 & 688 \\
\hline 6 & 100 & 14 & 185 & 22 & 200 & 30 & 286 & 38 & 359 & 46 & 400 & 54 & 500 & 62 & 592 & 70 & 693 \\
\hline 7 & 100 & 15 & 185 & 23 & 245 & 31 & 291 & 39 & 362 & 47 & 400 & 55 & 500 & 63 & 594 & & \\
\hline 8 & 100 & 16 & 189 & 24 & 259 & 32 & 295 & 40 & 378 & 48 & 400 & 56 & 500 & 64 & 595 & & \\
\hline
\end{tabular}

Table 2 shows that the exponential distribution is not validated, the difference between the empirical and theoretical distribution being higher than the critical value of the test. The normal distribution (Gauss-Laplace) and Weibull 2-parameter and 3-parameter distributions, with parameters calculated by different analytical methods, are validated [5]. The normalized 2-parameter Weibull distribution, for which the parameters are calculated with the least squares method, respectively with the maximum likelihood estimation, 
approximates the theoretical distribution best.

However, it can be stated with certainty that any of the validated distributions can characterize the functionality of the bucket wheel cutting teeth.

It is also noted the validation of the normal distribution. This is indicated by the literature for the characterization of the phenomenon of mechanical, electrical and thermal aging phenomena, which also happens in the studied case [6].

For the value of the shape parameter $\beta=2,\left(\beta_{1}=2,085 ; \beta_{2}=2,124 ; \beta_{3}=2,009\right)$ resulting from the calculations, Rayleigh distribution law criteria is met. This distribution law is a particular form of the Weibull distribution law and is characterized by the linear variation of the failure intensity [6].

Table 2. Comparative analysis of the theoretical distributions that characterize the 1400-MII type teeth

\begin{tabular}{|c|c|c|c|c|c|}
\hline $\begin{array}{l}\text { Theoretical } \\
\text { distribution }\end{array}$ & Equation of the reliability function, $R(t)$ & $\begin{array}{c}\text { Maximum } \\
\text { deviation, } \\
D_{\max }\end{array}$ & $\begin{array}{l}\text { Risk, } \\
\alpha(\%)\end{array}$ & $\begin{array}{l}\text { Critical } \\
\text { value, } \\
D_{\alpha, 76}\end{array}$ & Validation \\
\hline $\begin{array}{l}\text { Exponential, } \\
\text { ep }\end{array}$ & $e^{-0,003266 t}$ & 0,307194 & 0,5 & 0,203855 & No \\
\hline $\begin{array}{l}\text { Normal } \\
\text { (Gauss - } \\
\text { Laplace), } n v\end{array}$ & $\begin{array}{c}\frac{1}{2}-\Phi\left(\frac{t-347,271}{171,997}\right) \text { or } \\
1-\frac{1}{171,997} \frac{1}{\sqrt{2 \pi}} \int_{0}^{t} e^{-\frac{1}{2}\left(\frac{x-347,271}{171,997}\right)^{2}} d x\end{array}$ & 0,115382 & 20 & 0,125858 & Yes \\
\hline $\begin{array}{l}\text { Normalised } \\
\text { 2-parameter } \\
\text { Weibull, } W b p\end{array}$ & $e^{-\left(\frac{t}{393,987}\right)^{2.085}}$ & 0,088134 & 20 & 0,125858 & Yes \\
\hline $\begin{array}{l}\text { 3-parameter } \\
\text { Weibull, Wtm }\end{array}$ & $e^{-\left(\frac{t-3,42910^{-8}}{392,114}\right)^{2,124}}$ & $\mathbf{0 , 0 9 5 3 5 7}$ & 20 & 0,125858 & Yes \\
\hline $\begin{array}{l}\text { 2-parameter } \\
\text { Weibull, } W b v\end{array}$ & $e^{-\left(\frac{t}{395,848}\right)^{2,009}}$ & 0,084148 & 20 & 0,125858 & Yes \\
\hline
\end{tabular}

Figures 2 and 3 show the main reliability indicators that characterize the functionality of the teeth analyzed.

Analyzing the variations of the reliability and non-reliability functions, for an effective running time of the BWE of 200 hours, the reliability is $80 \%$. This means that after about 13 working days it is not yet necessary to replace the teeth. The amount of time in working days is calculated on the assumption that the BWE actually works on average 15 hours a day. The value of reliability for 200 hours, in the case of type 1400 MII cutting teeth is very good [4].

For the up to 100 hours of operating time, there is a fall in reliability to about $93 \%$. This decrease is absolutely normal due to the wear phenomenon. The period is characterized by a small value of the slope of the reliability curve, which suggests a low wear speed. After 100 hours, the slope of the curve increases, which indicates the increase in tooth wear. This behavior in operation also results from the failure rate variation curves, for which this same interval is characterized by low failure intensity [7].

For the average 348 hours of use time of the cutting teeth, it corresponds a $50 \%$ reliability. If an average operating time of 500 hours is imposed, the tooth reliability is only $20 \%$. This means that out of 100 new teeth mounted at the same time, after 500 hours of operation, only 20 will be in operation. The other 80 teeth are changed due to reaching the admissible wear limit. The rapid decrease in reliability from 80 to $20 \%$, with an increase in 
the time from 200 to 500 hours, shows the increase in wear speed. This increase is indicated by the steepness of the reliability curve slope and the increase in the intensity of wear $[8,9]$.

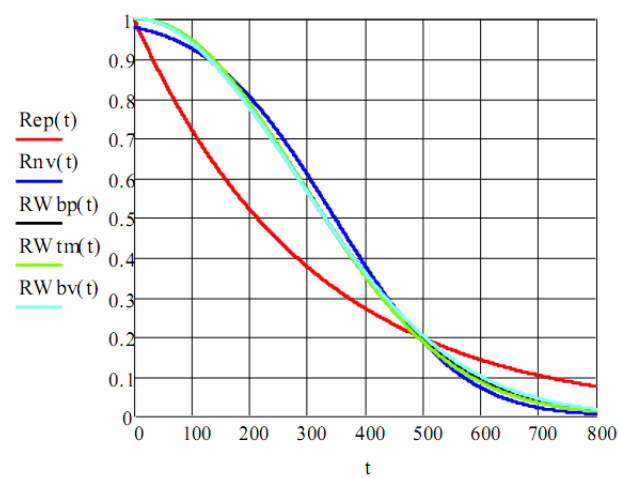

Fig. 2. Variation of the reliability function for the 1400 MII type teeth.

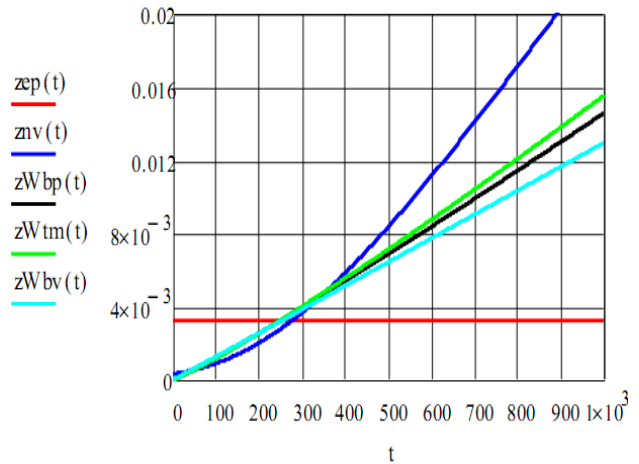

Fig. 3. Variation of the failure rate for the 1400 MII type teeth.

\section{Estimation of the average usage time of 1400-3GX type cutting tooth}

The field studies for the 1400-3GX type cutting teeth were performed on EsRc-1400 BWEs in the Berbești and Roşia open pit mines on a sample of 40 teeth.

Effective operating times-to-failure (change due to wear above the permissible limit), in hours, form the statistical series of type (S1) shown in table 3.

Table 3. Values of the operating time until failure for the cutting teeth type 1400-3GX

\begin{tabular}{|c|c|c|c|c|c|c|c|c|c|c|c|c|c|}
\hline No. & $T_{i}, h r s$ & No. & $T_{i}, h r s$ & No. & $T_{i}, h r s$ & No. & $T_{i}, h r s$ & No. & $T_{i}, h r s$ & No. & $T_{i}, h r s$ & No. & $T_{i}, h r s$ \\
\hline 1 & 80 & 7 & 185 & 13 & 198 & 19 & 283 & 25 & 365 & 31 & 400 & 37 & 495 \\
\hline 2 & 95 & 8 & 186 & 14 & 200 & 20 & 283 & 26 & 383 & 32 & 477 & 38 & 500 \\
\hline 3 & 95 & 9 & 190 & 15 & 200 & 21 & 298 & 27 & 389 & 33 & 481 & 39 & 582 \\
\hline 4 & 175 & 10 & 192 & 16 & 275 & 22 & 300 & 28 & 390 & 34 & 483 & 40 & 591 \\
\hline 5 & 175 & 11 & 195 & 17 & 279 & 23 & 357 & 29 & 399 & 35 & 490 & & \\
\hline 6 & 180 & 12 & 195 & 18 & 281 & 24 & 359 & 30 & 400 & 36 & 493 & & \\
\hline
\end{tabular}

Figures 4 and 5 show the variation of the main reliability indicators that characterize the functionality of the cutting teeth. Table 4 shows the comparative analysis of the theoretical distributions that characterize the 1400-3GX type teeth [10].

Analyzing the variations of the reliability and non-reliability functions, for an effective running time of the BWE of 200 hours, the reliability is $80 \%$. This means that after about 13 working days it is not yet necessary to replace the teeth. The amount of time in working days is calculated on the assumption that the BWE actually works on average 15 hours a day. The value of reliability for 200 hours, in the case of type 1400 MII cutting teeth is very good [3].

For the up to 100 hours of operating time, there is a fall in reliability to about $95 \%$. This decrease is absolutely normal due to the wear phenomenon. The period is characterized by a small value of the slope of the reliability curve, which suggests a low wear speed. After this time, the slope of the curve increases abruptly, which indicates a pronounced increase of the tooth wear speed. This behavior in operation also results from the failure rate variation curves, for which this same interval is characterized by low failure intensity[5]. 
Table 4. Comparative analysis of the theoretical distributions that characterize the 1400-3GX type teeth

\begin{tabular}{|c|c|c|c|c|c|}
\hline $\begin{array}{l}\text { Theoretical } \\
\text { distribution }\end{array}$ & Equation of the reliability function, $R(t)$ & $\begin{array}{c}\text { Maximum } \\
\text { deviation, } \\
D_{\max }\end{array}$ & $\begin{array}{l}\text { Risk, } \\
\alpha(\%)\end{array}$ & $\begin{array}{c}\text { Critical } \\
\text { value, } \\
D_{\alpha, 76} \\
\end{array}$ & Validation \\
\hline $\begin{array}{l}\text { Exponential, } \\
\text { ep }\end{array}$ & $e^{-0,03590 t}$ & 0,399666 & 0,5 & 0,268027 & No \\
\hline $\begin{array}{l}\text { Normal (Gauss } \\
\text { - Laplace), } n v\end{array}$ & $\begin{array}{c}\frac{1}{2}-\Phi\left(\frac{t-314,350}{138,780}\right) \text { or } \\
1-\frac{1}{138,780} \frac{1}{\sqrt{2 \pi}} \int_{0}^{t} e^{-\frac{1}{2}\left(\frac{x-314,350}{138,780}\right)^{2}} d x\end{array}$ & 0,158882 & 20 & 0,165472 & Yes \\
\hline $\begin{array}{l}\text { Normalised 2- } \\
\text { parameter } \\
\text { Weibull, } \mathrm{Wbp} \\
\end{array}$ & $e^{-\left(\frac{t}{356,750}\right)^{2,346}}$ & 0,137006 & 20 & 0,165472 & Yes \\
\hline $\begin{array}{l}\text { 3-parameter } \\
\text { Weibull, Wtm }\end{array}$ & $e^{-\left(\frac{t-1,36310^{-8}}{354,564}\right)^{2,414}}$ & 0,141894 & 20 & 0,165472 & Yes \\
\hline $\begin{array}{l}\text { 2-parameter } \\
\text { Weibull, } W b v\end{array}$ & $e^{-\left(\frac{t}{349,708}\right)^{2,314}}$ & 0,123908 & 20 & 0,165472 & Yes \\
\hline
\end{tabular}

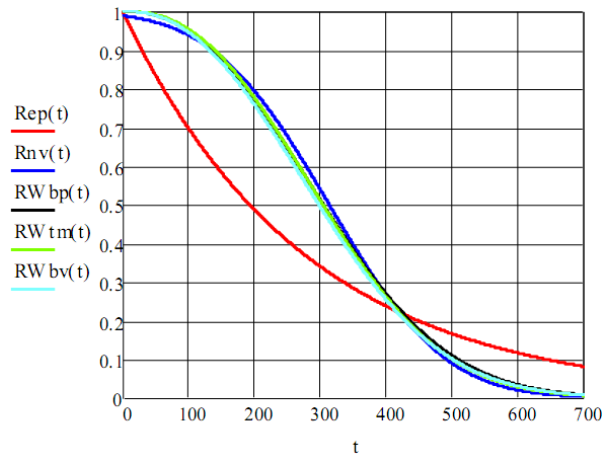

Fig. 4. Variation of the reliability function for the 1400-3GX type teeth.

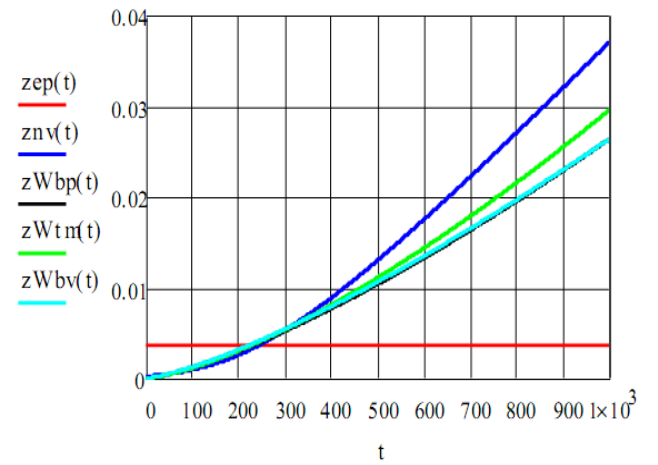

Fig. 5. Variation of the failure rate for the 14003GX type teeth.

For the average 314 hours of use time of the cutting teeth, it corresponds a $50 \%$ reliability. If an average operating time of 500 hours is imposed, the tooth reliability is only $10 \%$. This means that out of 100 new teeth mounted at the same time, after 500 hours of operation, only 10 will be in operation. The difference of 90 teeth are changed due to reaching the admissible wear limit [4].

The rapid decrease in reliability from 80 to $10 \%$, with an increase in the time from 200 to 500 hours, shows the increase in wear speed. This increase is indicated by the steepness of the reliability curve slope and the increase in the intensity of wear.

\section{Estimation of the average usage time of 1300-A0M type cutting tooth}

The field studies for the 1300-A0M type cutting teeth were performed on EsRc-1400 BWEs 
in the Berbești open pit mines and on a E-470 BWE in the Olteț open pit mine, on a sample of 41 teeth [2].

Effective operating times-to-failure ( $\left.\mathrm{t}_{\mathrm{i}}\right)$ in hours, form the statistical series of type (S1) shown in table 5 [1].

Table 6 shows the comparative analysis of the theoretical distributions that characterize the 1300-A0M type teeth and figures 6 and 7 show the variation of the main reliability indicators that characterize the functionality of this type of teeth. These are the main indicators that allow differentiation of the functional characteristics of the teeth, viewed from the point of view of actual operating times [1].

Table 5. Values of the operating time untill failure for rhe cutting teeth type 1300-A0M

\begin{tabular}{|c|c|c|c|c|c|c|c|c|c|c|c|c|c|}
\hline No. & $T_{i}, h r s$ & No. & $T_{i}, h r s$ & No. & $T_{i}, h r s$ & No. & $T_{i}, h r s$ & No. & $T_{i}, h r s$ & No. & $T_{i}, h r s$ & No. & $T_{i}, h r s$ \\
\hline 1 & 95 & 7 & 193 & 13 & 269 & 19 & 299 & 25 & 398 & 31 & 585 & 37 & 789 \\
\hline 2 & 98 & 8 & 195 & 14 & 283 & 20 & 300 & 26 & 425 & 32 & 597 & 38 & 823 \\
\hline 3 & 100 & 9 & 196 & 15 & 290 & 21 & 351 & 27 & 489 & 33 & 600 & 39 & 861 \\
\hline 4 & 183 & 10 & 200 & 16 & 293 & 22 & 385 & 28 & 490 & 34 & 642 & 40 & 887 \\
\hline 5 & 188 & 11 & 250 & 17 & 296 & 23 & 385 & 29 & 500 & 35 & 659 & 41 & 950 \\
\hline 6 & 189 & 12 & 265 & 18 & 298 & 24 & 393 & 30 & 542 & 36 & 725 & & \\
\hline
\end{tabular}

Table 6. Comparative analysis of the theoretical distributions that characterize the 1300 -A0M type teeth

\begin{tabular}{|c|c|c|c|c|c|}
\hline $\begin{array}{l}\text { Theoretical } \\
\text { distribution }\end{array}$ & Equation of the reliability function, $R(t)$ & $\begin{array}{c}\text { Maximum } \\
\text { deviation, } \\
D_{\max } \\
\end{array}$ & \begin{tabular}{|c|} 
Risk, \\
$\alpha$ \\
$(\%)$ \\
\end{tabular} & $\begin{array}{c}\text { Critical } \\
\text { value, } \\
D_{\alpha, 76} \\
\end{array}$ & Validation \\
\hline $\begin{array}{l}\text { Exponential, } \\
e p\end{array}$ & $e^{-0,002711 t}$ & 0,325905 & 0,5 & 0,264824 & No \\
\hline $\begin{array}{l}\text { Normal } \\
\text { (Gauss - } \\
\text { Laplace), } n v\end{array}$ & $\begin{array}{c}\frac{1}{2}-\Phi\left(\frac{t-413,561}{233,599}\right) \text { or } \\
1-\frac{1}{233,599} \frac{1}{\sqrt{2 \pi}} \int_{0}^{t} e^{-\frac{1}{2}\left(\frac{x-413,561}{233,599}\right)^{2}} d x\end{array}$ & 0,162410 & 20 & 0,163492 & Yes \\
\hline \begin{tabular}{|l|} 
Normalised 2- \\
parameter \\
Weibull, $W b p$
\end{tabular} & $e^{-\left(\frac{t}{465,906}\right)^{1,954}}$ & 0,130895 & 20 & 0,163492 & Yes \\
\hline $\begin{array}{l}\text { 3-parameter } \\
\text { Weibull, Wtm }\end{array}$ & $e^{-\left(\frac{t+2,413 \cdot 10^{-8}}{465,458}\right)^{1,835}}$ & 0,115663 & 20 & 0,163492 & Yes \\
\hline $\begin{array}{l}\text { 2-parameter } \\
\text { Weibull, } W b v\end{array}$ & $e^{-\left(\frac{t}{448,708}\right)^{1,902}}$ & 0,103994 & 20 & 0,163492 & Yes \\
\hline
\end{tabular}

Analyzing the variations of the reliability/non-reliability function graphs, for an effective running time of the BWE of 200 hours, the reliability is $80 \%$. This means that after about 13 working days it is not yet necessary to replace the teeth. The amount of time in working days is calculated on the assumption that the BWE actually works on average 15 hours a day. The value of reliability for 200 hours, in the case of this type of cutting teeth is very good [11].

For the first 100 hours of operating time $(\mathrm{t}=100, \mathrm{R}(100)=0.95)$, there is decrease in reliability to about $95 \%$. This is normal due to the wear. The period is characterized by a 
gentle slope of the reliability curve, which means a slow wear. After 100 hours, the slope of the curve steepens indicating increase in tooth wear and break-down. The same results from the failure rate variation curves [6].

For the average 410 hours of use time of the cutting teeth we have a $50 \%$ reliability. If an average operating time of 500 hours is imposed, the tooth reliability is only $50 \%$. This means that out of 100 new teeth mounted at the same time, after 500 hours of operation, only 30 will be in operation while the other teeth are changed due to reaching the admissible wear limit [10].

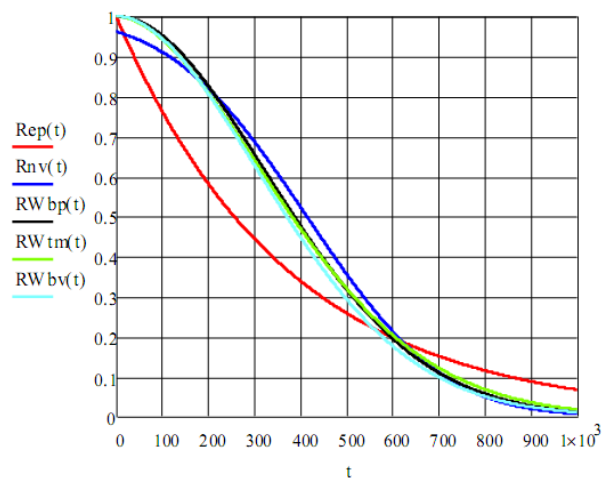

Fig. 6. Variation of the reliability function for the 1300-A0M type teeth.

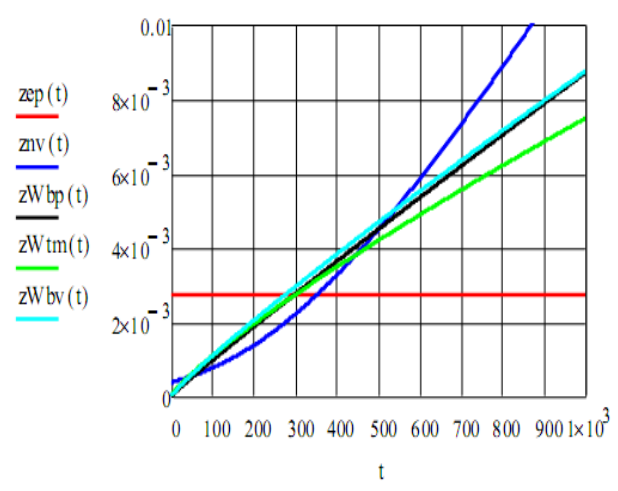

Fig. 7. Variation of the failure rate for the 1300A0M type teeth.

The rapid decrease in reliability from 80 to $30 \%$, with an increase in the time from 200 to 500 hours, shows and increased wear speed. This increase is indicated by the steepness of the reliability curve slope and the increase in the intensity of wear.

\section{Conclusion}

Taking into account the operating conditions for the cutting teeth, the determination of the average time-of-use can only be done using statistical calculations. Operating conditions mean excavation in non-homogeneous material, abrasive wear phenomenon, being subjected to various type of stresses, especially shocks. Besides, there are different teeth requirements based on their placement on the buckets and the excavation technology used.

Thus, it was chosen by the mining company, to carry out the reliability study on the three types of teeth used in production. As a result of the study, besides the average use time, other characteristics proving the quality of the teeth resulted.

The reliability study was performed using representative samples of each type of tooth. By tracking the teeth working under actual operating conditions the effective operation of each tooth until replacement was recorded.

A first conclusion is the identical behavior of all the three types of teeth for up to 200 hours of operation. Behavior is characterized by equal wear rates. This demonstrates that the three types of teeth when mounted are characterized by the same cutting characteristics (both geometric and strength).

Differentiation occurs after 200 hours of operation when the wear rate increases, more for the 1400-3GX type and less for the 1300-A0M type. This means that the geometric and strength characteristics of each type of tooth changes. Thus, for a reliability level of $50 \%$, the average running time differs substantially, the best being the 1300-A0M type tooth with an average of 410 hours. 
The assessments made on the behavior of the three types of teeth tested lead to their ranking in terms of technical and functional characteristics. The first is the 1300-A0M type tooth, the second is the 1400-MII type tooth, and the third is the 1400-3GX type tooth.

Differences between the three types of teeth appear from the different constructivefunctional solutions adopted for their assimilation. These are related to geometry and strength characteristics, especially in terms of the thickness of the hardened material on the cutting edges, as well as its strength.

\section{References}

1. O.B. Tomuș, et al, Studiul posibilităţilor de creştere a performanţelor în exploatare a rotorului excavatoarelor utilizate în carierele S.N.L.Oltenia, ţinând seama de caracteristicile la tăiere ale lignitului şi rocilor din descopertă. Contract nr. 1170/S/06.12.2006 cu S.N.L.O. Tg-Jiu (2006)

2. O.B. Tomuş, et al, Cercetări teoretice şi experimentale privind creșterea gradului de utilizare a utilajelor de excavatoare în carierele de lignit aparţinând S.C. Complexul Energetic Turceni S.A. Contract nr. 1/2006 cu S.C. Complexul Energetic Turceni S.A. (2006)

3. D. Jula, G. Praporgescu, S. Mihăilescu, O.B. Tomuş, I.Deaconu, Aspecte privind determinarea fiabilităţii utilajelor din carierele de lignit, Lucrările ştiinţifice ale simpozionului internaţional multidisciplinar "Universitaria SIMPRO", Volumul: Maşini şi echipamente tehnologice. Editura UNIVERSITAS, Petroşani (2006)

4. O.B.Tomuş, Studiul posibilităţilor de creştere a performanţelor rotorului excavatoarelor utilizate in carierele de lignit. Teză de doctorat. Petroşani (2009)

5. F. Baicu, Elemente de fiabilitate, Editura Victor, Bucureşti (2005)

6. D. Jula, I. Dumitrescu, Fiabilitatea sistemelor de transport, Editura Focus, Petroşani (2009)

7. G. Ladányi, E. Nagy, Z.Virág, Study on dynamics of caterpillar track bodies, VII International Conference on Mining Techniques, TUR 2011, on CD: TUR 2011 Książka.pdf. (2011)

8. N. Balosin, A. Magyari, D. Jula, Annals of the University of Petroşani, Mechanical Engineering. 11 (XXXVIII) (2009)

9. S.M. Radu, F.D. Popescu, A. Andras, B.I. Kertesz, O.B. Tomus, QUALITY-ACCESS TO SUCCESS, 20, 1, 359-364 (2019)

10. I. Mitran, F.D. Popescu, M.S. Nan, S.S. Soba, Computer Assisted Statistical Methods for Process Reliability Analysis, Proceedings of the 15th American Conference on Applied Mathematics, Houston, USA, Recent Advances in Applied Mathematics and Computational and Information Sciences, I, ISBN: 978-960-474-071-0, ISSN: 1790-5117, 166-170 (2009)

11. D. Pasculescu, T. Niculescu, Study of transient inductive-capacitive circuits using data acquisition systems, 15th International Multidisciplinary Scientific Geoconference, Location: Albena, Bulgaria, Informatics, Geoinformatics and Remote Sensing, I, 323-329 (2015) 